\title{
Liver Function Tests in Normal Pregnant Women
}

\author{
David Nzioka Mutua $^{1,2^{\star}}$, Eliud Nyaga Mwaniki Njagi ${ }^{1}$ and George Orinda ${ }^{1}$
}

${ }^{1}$ Department of Biochemistry and Biotechnology, School of Pure and Applied Sciences, Kenyatta University, Nairobi, Kenya

${ }^{2}$ Department of Medical Biochemistry, School of Medicine and Health Sciences, Kenya Methodist University, Meru, Kenya

*Corresponding author: David Nzioka Mutua, Department of Biochemistry and Biotechnology, School of Pure and Applied Sciences, Kenyatta University, PO Box43844-00100, Nairobi, Kenya, Tel: +254720261585; E-mail: mutua.david@ku.ac.ke

Received date: June 13, 2018; Accepted date: June 28, 2018; Published date: June 30, 2018

Copyright: @ 2018 Mutua DN, et al. This is an open-access article distributed under the terms of the Creative Commons Attribution License, which permits unrestricted use, distribution, and reproduction in any medium, provided the original author and source are credited.

\begin{abstract}
Changes in liver function tests (LFTs) are normal during pregnancy. However, severe liver disease, although rare, can occur and must be recognized at an early stage to reduce maternal and fetal morbidity and mortality. It is important to differentiate between normal physiological changes and disease pathology. This review highlights the important LFT changes that take place during normal pregnancy.
\end{abstract}

Abbreviations: LFTs: Liver function tests; ALT: Alanine aminotransferase; GGT: Gamma glutamyl transferase;AST: Aspartate aminotransferase; ALP: Alkaline phosphatase

Keywords Liver function tests; Pregnancy; Pathology; Hepatobiliary system; Hepatic enzymes

\section{Introduction}

Changes in liver biochemical profile are normal during pregnancy $[1,2]$. However, severe liver disease, although rare, can occur and must be recognized at an early stage to reduce morbidity and mortality for mother and infant [3,4]. It is important to differentiate between normal physiological changes and disease pathology $[5,6]$. This review highlights LFTs and the important changes that take place during normal pregnancy (Table 1).

A comprehensive electronic database review was conducted, using MEDLINE and PUBMED to search for studies published between 2008 and 2018, investigating LFTs during pregnancy. Articles were included if the analyses studied were measured in healthy pregnant women and if the LFT marker was measured and reported per trimester. For each reported parameter, data were extracted from as many studies as possible. In most studies, reference ranges were reported based on minimal and maximal values, but, when possible, the 2.5 and 97.5 percentiles were used to describe the normal range. The LFT reference values differed between populations (Table 2), mostly driven by a combination of genetic, demographic, nutritional, and environmental factors [1-3]. The combined literature is the basis for the conclusive nature of this review.

\section{Liver Function Tests}

LFTs are commonly ordered panel of blood tests that evaluate liver function, liver damage and biliary system function including intra and extra hepatic bile ducts and gall bladder [7]. Additionally, LFTs evaluate aspects of physiology outside hepatobiliary system, for instance they provide insights into coagulation, haemolysis, nutrition, bone turnover and other conditions $[8,9]$.
The specific tests included in LFTs are hepatic enzymes, synthetic function tests, and bilirubin. In common practice, there are four hepatic enzymes of interest: aspartate aminotransferase (AST), alanine aminotransferase (ALT), alkaline phosphatase (ALP), and gamma glutamyl transferase (GGT) [10,11]. AST and ALT are collectiv ely known as aminotransferases or transaminases. Tests for synthetic function i.e., how well the liver can synthesis new compounds particularly proteins, include serum albumin and International Normalized Ratio [12,13].

\section{Aspartate and Alanine Aminotransferase}

AST is found in liver, cardiac muscles, brain, skeletal muscles, erythrocytes and kidney. ALT is found predominantly in liver. Therefore, increases in ALT are more specific than AST for hepatobiliary disease. In the hepatocytes, AST is cytoplasmic while ALT is intramitochodrial. A typical hepatitic picture therefore comprises ALT rise, accompanied by lesser elevation in AST and GGT $[5,7]$.

There is no agreement on the effect of pregnancy on serum AST and ALT. In a few studies, AST and/ or ALT levels slightly increase in the third trimester. However, in most studies, AST and ALT levels remain within the normal range for non-pregnant state (Table 1). Uterine muscle contractions during labor may increase AST or ALT activity levels [3]. Thus, serum ALT or AST values above normal ranges before labor are pathological and further investigations are recommended. Hence, measurement of AST and ALT levels is the most informative test in the diagnosis of hepatobiliary diseases [14].

Elevated AST is caused by: Any form of hepatocellular disease (e.g. cirrhosis, hepatitis, drug toxicity and fatty liver), any form of biliary disease (e.g., choledocholithiasis, cholecytitis, cholangitis, and cholangiocarcinoma, basically any disease which starts with syllable "chole". Often, diseases of biliary system are collectively referred to as cholestatic disease), rhabdomyolysis (muscle breakdown), acute myocardial infraction and hemolysis. Meanwhile, elevated ALT is reported in any form of hepatocellular disease and any form of biliary disease $[9,10]$.

ALT greater than AST in most chronic liver disease not caused by alcohol (e.g., chronic hepatitis), until cirrhosis develops at which point 
AST is greater than ALT. AST: ALT greater than 2 in a patient with probable liver disease is strongly suggestive of alcohol as an etiology. AST: ALT greater than is suggestive of an extrahepatic source of AST (e.g., rhabdomyolysis, acute myocardial infraction) $[7,12]$.

\section{Alkaline Phosphatase and Gamma Glutamyl Transferase}

ALP is actually a collection of isoenzymes, present throughout the body. The most clinically relevant ALP is found in liver, bones, the biliary duct, white blood cells, small bowel and placenta. ALP functions best in alkaline conditions. It is used to evaluate for liver or bone disease. Normal ALP levels vary greatly depending on age, gender and blood type. The normal range for serum ALP is 30-125 unit/L $[8,15]$.

Serum ALP levels are elevated in late pregnancy, usually in the third trimester. This increase is mainly due to the production of placental isoenzyme rather than elevation of hepatic isoenzyme. Additionally, there is an increased production of the bone isoenzyme with gestational age as a result of fetal bone development [16]. The diversity of the sources of serum ALP shows that it is not a reliable and/ or a suitable test for liver disease during late pregnancy [3].

Etiologies for elevated ALP include: any form of biliary pathology, any form of hepatocellular disease, high bone turnover or bone loss (e.g., bone metastases, paget's disease, hyperthyroidism, hyperparathyroidism), pulmonary embolism, congestive heart failure, ulcerative colitis, pneumonia, and normal pregnancy [6-10].

While serum gamma glutamyl transferase (GGT) activity is generally considered normal during gestation, emerging studies show decrease in serum GGT levels with gestational age. Significant differences have been noted in the second and third trimesters of pregnancy when compared with non-pregnant women [3]. Serum GGT activity has also be found to vary significantly between first and third semester of pregnancy in women with morning sickness. Expectant mothers with viral hepatitis in first trimester have higher serum GGT levels than those with the infection in the third semester. The same tread has been noted among those taking oral contraceptives. These observations suggest that hepatic synthesis of GGT may be inhibited by sex hormones, thus decreasing serum GGT levels with gestational age $[17,18]$.

Etiologies of elevated GGT include: any form of biliary system disease, any form of hepatocellular disease, alcohol abuse, diabetes, renal failure and drugs like phenytoin. Etiologies of reduced ALP include: hypothyroidism, pernicious anemia, zinc deficiency, autoimmune disorders, celiac disease, and Wilson's disease. There is no reliable means of measuring individual isoenzymatic forms of ALP in clinical setting, hence the need for GGT $[7,8]$.

GGT catalyzes the transfer of a gamma-glutamyl group from glutathione to an amino acid, peptide or water. It is also present in increased broad range of hepatobiliary disease with similar sensitivity and specificity as ALP. However, GGT is not present in bone in significant amounts $[3,6]$.

\section{Serum Albumin}

Albumin is a globular protein, formally called human serum albumin. It is produced by the liver and comprises about half of the total protein in blood $[16,18,19]$. Albumin is negatively charged at physiologic $\mathrm{pH}$; therefore binds negatively charged cations (e.g., $\mathrm{Ca}^{2+}$, $\mathrm{Na}^{+}, \mathrm{K}^{+}$), some hormones, conjugated bilirubin and some medications. Its primary function is maintenance of capillary oncotic pressure. Other lesser roles include determining kidney function, liver function, and nutrition $[20,21]$.

Serum albumin concentration decreases with pregnancy age. The decrease in serum albumin levels is attributed to pregnancy-related plasma expansion. Indeed, intravascular albumin mass and the rate of metabolism (anabolism or catabolism) in pregnant women is within the normal limits for non-pregnant women $[4,22,23]$.

Etiologies of hyperalbuminemia include: Liver disease, dehydration, and impaired renal function. Etiologies of hypoalbuminemia include: decreased synthesis (due to chronic liver disease and malnutrition), increased loss (nephrotic syndrome and protein-losing enteropathy), internal redistribution (increased capillary permeability cause pitting edema in legs and ascites in abdomen), impaired renal function, burns and lymphatic disease or cancer $[6,8,24]$.

\section{Bilirubin}

Bilirubin comes from haemoglobin (Hgb) as red blood cells (RBCs) breakdown either through physiological regeneration at the end of normal lifespan or as a consequence of pathologic hemolysis. Hgb releases heme which is converted inside macrophages to biliverdin which is then converted into unconjugated bilirubin (indirect bilirubin) which travels through the liver where it combines with glucuronic acid to form conjugated bilirubin (also known as bilirubin diglucuronide or direct bilirubin [23-25]. This step is important because unconjugated bilirubin is water insoluble which impairs its ability to be excreted in bile, while conjugated bilirubin is water soluble. Additionally, a fraction of conjugated bilirubin binds to circulating albumin, a form of bilirubin called delta-bilirubin. This is clinically relevant because it helps to explain why the resolution of elevated bilirubin levels can lag behind resolution of other lab abnormalities following correction of some form of hepatobiliary disease. The delta-bilirubin may persist for as long as the albumin is in circulation which has a half-life of several weeks [26-30].

There are several variations on how bilirubin is reported on an LFT panel, uncommonly, although it would make more sense, it is reported as conjugated and unconjugated. Instead it is reported as conjugated and total bilirubin or sometimes just total bilirubin $[4,7,30,31]$

Total bilirubin activity decreases with gestational age. Unconjugated bilirubin levels are also lower in expectant mothers than in nonpregnant women in all three trimesters. During the first trimester, conjugated bilirubin concentration in pregnant women is the same as in the non-pregnant women; however, it decreases in the second and third trimesters. Hemodilution with pregnancy age partly explains the corresponding decrease in bilirubin concentration [10,16,32-34].

Hyperbilirubinemia, total bilirubin levels greater than $1.3 \mathrm{mg} / \mathrm{dL}$, cause jaundice and icterus. Continued hyperbilirubinemia can cause kernicterus or brain damage $[3,35]$. Hyperbilirubinemia is caused by biliary obstruction, liver diseases, alcoholism, trauma, starvation, and hypothyroidism. Etiologies of high bilirubin depend greatly on which type of bilirubin is elevated [27]. High unconjugated and conjugated bilirubin is found in any diffuse hepatocellular or biliary process. High unconjugated bilirubin suggests hemolysis or genetic disease such as Gilbert's and Crigler-Najjar syndromes in which there are problems with bilirubin conjugation. 
Citation: Mutua DN, Mwaniki Njagi EN, Orinda G (2018) Liver Function Tests in Normal Pregnant Women. J Liver 7: 228. doi:

Page 3 of 4

\begin{tabular}{|l|l|}
\hline Parameter & Alteration from non-pregnant state \\
\hline Aspartate aminotransferase & $\downarrow$ \\
\hline ALT & $\leftrightarrow$ \\
\hline Alanine Phosphatase & $\uparrow$ \\
\hline Gamma Glutamyl Transferase & $\leftrightarrow$ \\
\hline Bilirubin & $\leftrightarrow$ \\
\hline Albumin & $\downarrow$ \\
\hline
\end{tabular}

Meanwhile, high conjugated bilirubin can be seen in early/mild biliary system disease and in genetic disease such as Dubin-Johnson and Rotor syndromes $[10,16]$.

High bilirubin is only dangerous in infancy where it causes bilirubin-induced neurologic dysfunction. This occurs in neonates who have bilirubin levels $>20 \mathrm{mg} / \mathrm{dL}$. Bilirubin is directly toxic to neurons, particularly in basal ganglia and brainstem nuclei. Manifestations range from sleepiness and subtle hypotonia to seizures and death. Kernicterus, the syndrome of permanent sequel, is seen among infants who survive [13,14,36-40].

Table 1: Liver Function Test Changes during Normal Pregnancy.

\begin{tabular}{|c|c|c|c|c|c|c|}
\hline Variable & Trimester & Gujarat, India[16] & North Kerala, India [31] & Southern India [36] & Nigeria [33] & USA [37] \\
\hline \multirow{3}{*}{ AST (U/L) } & $1 \mathrm{st}$ & $23.31 \pm 18.18$ & $22.51 \pm 3.07$ & $21.9 \pm 5.5$ & $21.54 \pm 8.66$ & $3-23$ \\
\hline & 2nd & $23.88 \pm 14.99$ & - & $20.1 \pm 6.9$ & $22.19 \pm 4.50$ & $3-33$ \\
\hline & $3 r d$ & $34.92 \pm 26.94$ & $26.68 \pm 2.98$ & $19.9 \pm 8.0$ & $16.60 \pm 7.39$ & $4-32$ \\
\hline \multirow{3}{*}{ ALT (U/L) } & $1 \mathrm{st}$ & $23.54 \pm 11.92$ & $28.09 \pm 2.97$ & $17.9 \pm 14.4$ & $31.69 \pm 9.11$ & $3-30$ \\
\hline & 2nd & $23.42 \pm 8.68$ & - & $14.8 \pm 7.3$ & $31.24 \pm 5.90$ & $2-33$ \\
\hline & $3 r d$ & $34.22 \pm 23.57$ & $32.55 \pm 2.56$ & $13.2 \pm 5.2$ & $32.39 \pm 10.94$ & $2-25$ \\
\hline \multirow{3}{*}{ ALP (U/L) } & $1 \mathrm{st}$ & $152.5 \pm 49.5$ & $67.02 \pm 10.94$ & $70.4 \pm 22.4$ & - & $17-88$ \\
\hline & 2nd & $195.8 \pm 34.7$ & - & $90.3 \pm 40.7$ & - & $25-126$ \\
\hline & $3 r d$ & $399.1 \pm 147.4$ & $251.15 \pm 35.43$ & $171.0 \pm 75.2$ & - & $38-229$ \\
\hline \multirow{3}{*}{ GGT (U/L) } & $1 \mathrm{st}$ & $27.02 \pm 3.80$ & $18.33 \pm 2.14$ & $12.9 \pm 9.1$ & - & $2-23$ \\
\hline & $2 n d$ & $24.78 \pm 5.81$ & - & $11.8 \pm 4.8$ & - & $4-22$ \\
\hline & $3 r d$ & $17.10 \pm 4.61$ & $13.46 \pm 1.62$ & $11.1 \pm 5.1$ & - & $3-26$ \\
\hline \multirow{3}{*}{$\begin{array}{l}\text { Total bilirubin } \\
(\mathrm{mg} / \mathrm{dL})\end{array}$} & $1 \mathrm{st}$ & $0.63 \pm 0.36$ & $0.68 \pm 0.08$ & $0.40 \pm 0.22$ & $6.92 \pm 1.98$ & $0.1-0.4$ \\
\hline & 2nd & $0.68 \pm 0.32$ & - & $0.37 \pm 0.12$ & $7.05 \pm 3.28$ & $0.1-0.8$ \\
\hline & $3 r d$ & $0.55 \pm 0.26$ & $0.56 \pm 0.06$ & $0.44 \pm 0.24$ & $9.23 \pm 3.93$ & $0.1-1.1$ \\
\hline \multirow{3}{*}{$\begin{array}{l}\text { Direct } \\
\text { Bilirubin } \\
\text { (mg/dL) }\end{array}$} & $1 \mathrm{st}$ & $0.17 \pm 0.14$ & $0.26 \pm 0.06$ & $0.17 \pm 0.08$ & - & $0-0.1$ \\
\hline & $2 n d$ & $0.13 \pm 0.09$ & - & $0.15 \pm 0.05$ & - & $0-0.1$ \\
\hline & $3 r d$ & $0.08 \pm 0.05$ & $0.18 \pm 0.05$ & $0.44 \pm 0.24$ & - & $0-0.1$ \\
\hline \multirow{3}{*}{$\begin{array}{l}\text { Total Protein } \\
(\mathrm{mg} / \mathrm{dL})\end{array}$} & $1 \mathrm{st}$ & $7.30 \pm 0.40$ & $7.19 \pm 0.21$ & $7.6 \pm 0.46$ & - & $6.2-7.6$ \\
\hline & 2nd & $7.22 \pm 0.59$ & - & $7.0 \pm 0.38$ & - & $5.7-6.9$ \\
\hline & $3 r d$ & $7.15 \pm 0.72$ & $6.62 \pm 0.15$ & $6.7 \pm 0.38$ & - & $5.6-6.7$ \\
\hline \multirow{3}{*}{$\begin{array}{l}\text { Albumin } \\
\text { (mg/dL) }\end{array}$} & $1 \mathrm{st}$ & $4.31 \pm 0.42$ & $3.70 \pm 0.145$ & $4.16 \pm 0.21$ & - & $3.1-5.1$ \\
\hline & 2nd & $3.79 \pm 0.54$ & - & $3.67 \pm 0.28$ & - & $2.6-4.5$ \\
\hline & $3 r d$ & $3.37 \pm 0.46$ & $3.43 \pm 0.14$ & $3.40 \pm 0.18$ & - & $2.3-4.2$ \\
\hline
\end{tabular}

Table 2: Comparison of liver function test reference values for pregnant women obtained from different countries. 


\section{Conclusion}

It is important to consider normal reference ranges specific to pregnancy when interpreting LFT results that may be altered by the normal changes of pregnancy. Serum ALP and albumin decreases while ALT increases significantly with gestational age. Meanwhile, AST, GGT, and bilirubin fluctuate but remain within the normal ranges established in non-pregnant women. Unless these normal, gestation-related alterations are taken into account when evaluating LFT values in a pregnant woman, physiologic adaptations of pregnancy can be misinterpreted as pathologic or, alternatively, pathologic findings may not be recognized.

\section{References}

1. US Department of Health and Human Services (2013) Pregnancy: Condition Information. National Institutes of Health.

2. Boundless (2015) Introduction to pregnancy and human development. In: Boundless Anatomy and Physiology, Boston.

3. Westbrook RH, Dusheiko G, Williamson C (2016) Pregnancy and liver disease. J Hepatol 64: 933-945.

4. Akinlaja $\mathrm{O}$ (2016) Hematological changes in pregnancy-The preparation for intrapartum blood loss. Obstetrics Gynecol International J 4: 00109.

5. Kaur S, Khan S, Nigam A (2014) Hematological profile and pregnancy: a review. International J Advances in Medicine 1: 68-70.

6. Azab EA, Albasha MO, Elhemady SY (2017) Haematological parameters in pregnant women attended antenatal care at sabratha teaching hospital in northwest, Libya. Pathol Laboratory Med 2: 60-68.

7. Al-Jameil N, Hajera HT, Al-Mayouf Huda H, Al-Shenefy Amal Ali, Khan FA (2015) Liver function tests as probable markers of preeclampsia-A Prospective study conducted in Riyadh. J Clinical Analytical Med 6: 461-464.

8. Boregowda G, Shehata HA (2013) Gastrointestinal and liver disease in pregnancy. Best Practice Res Clinical Obstetrics Gynaecol 27: 835-853.

9. Kwo PY, Cohen SM, Lim JK (2016) ACG Clinical Guideline: Evaluation of abnormal liver chemistries. Am J Gastroenterol 1: 18-35.

10. Dunia MR (2015) Effect normal pregnancy and duration on liver enzymes tests. Global J Medical Res 15: 2-5.

11. Cholongitas E, Burroughs AK (2008) Liver Diseases Specific to Pregnancy. Annals Gastroenterol 21: 164-172.

12. Das S, Char D, Sarkar S, Saha KT, Biswas S, et al. (2013) Evaluation of liver function test in normal pregnancy and preeclampsia: A case control. IOSR J Dental Medical Sci 12: 30-32.

13. Geenes V, Williamson C (2015) Liver disease in pregnancy. Best Practice Res Clinical Obstetrics Gynaecol pp: 1-13.

14. Jamjute P, Ahmad A, Ghosh T, Banfield P (2009) Liver function test and pregnancy. J Maternal-Fetal Neonatal Med 22: 274-283.

15. Kozic JR, Benton SJ, Hutcheon JA, Payne BA, Magee LA, et al. (2011) Abnormal liver function tests as predictors of adverse maternal outcomes in women with preeclampsia. J Obstet Gynaecol Can 33: 995-1004.

16. Gohel MG, Joshi AG, Anand JS, Makadia JS, Kamariya CP (2013) Evaluation of changes in liver function test in first, second and third trimester of normal pregnancy. International J Reprod Contracept Obstet Gynecol 2: 616-620.

17. Mishra N, Mishra VN, Thakur P (2016) Study of abnormal liver function test during Pregnancy in a tertiary care hospital in Chhattisgarh. J Obstet Gynecol India 66: S129-S135.

18. Ryan JM, Heneghan MA (2014) Pregnancy and the liver. Clinical Liver Disease 4: 51-54.

19. Rodríguez-Dennen F, Martínez-Ocaña J, Kawa-Karasik S, VillanuevaEgan S, Reyes-Paredes N, et al. (2016) Comparison of hemodynamic, biochemical and hematological parameters of healthy pregnant women in the third trimester of pregnancy and the active labor phase. BMC Pregnancy and Childbirth pp: 11-33.

20. Mei-Dan E, Wiznitzer A, Sergienko R, Hallak M, Sheiner E (2013) Prediction of preeclampsia: liver function tests during the first 20 gestational weeks. J Maternal-Fetal and Neonatal Medicine 26: 250-253.

21. Mitra AK, Patki PS, Mitra SK (2008) Liver disorders during pregnancy and their management. Antiseptic 105: 193-196.

22. Munazza B, Raza N, Naureen A, Khan SA, Fatima F, et al. (2011) Liver function tests in Preeclampsia. J Ayub Medical College Abbottabad 23: 1-3.

23. Nwosu DC, Nwanjo HU, Obeagu EI, Ibebuike JE, Ezeama MC, et al (2015) Changes in liver enzymes and lipid profile of pregnant women with malaria in Owerri, Nigeria. International J Current Res Academic Review 3: 376-383.

24. Odhiambo C, Oyaro B, Odipo R, Otieno F, Alemnji G, et al. (2015) Evaluation of locally established reference intervals for hematology and biochemistry parameters in western kenya. Plos one 10: e0123140.

25. Arika WM, Nyamai DW, Osano KO, Ngugi MP, Njagi ENM (2016) Biochemical markers of InVivo hepatotoxicity. J Clinical Toxicol 6: 297.

26. Santana-Morales MA, Quispe-Ricalde MA, Afonso-Lehmann RN, Berzosa P, Lorenzo-Morales J, et al. (2013) Haemoglobin levels for population from Gambo, a rural area of Ethiopia, and their association with anemia and malaria. Malaria J 12: 435.

27. Samaneka WP, Mandozana G, Tinago W, Nhando N, Mgodi NM, et al. (2016) Adult hematology and clinical chemistry laboratory reference ranges in a zimbabwean population. Plos one 11: e0165821.

28. Rana S, Karumanchi SA, Lindheimer MD (2014) Angiogenic factors in diagnosis, management, and research in Preeclampsia. Hypertension 63: 198-202.

29. Shekhar S, Diddi S (2015) Liver disease in pregnancy. Taiwanese J Obstetrics Gynecol 54: 475-482.

30. Tran TT, Ahn J, Reau NS (2016) ACG Clinical Guideline: Liver Disease and Pregnancy. Am J Gastroenterol pp: 1-14.

31. Venugopal S, Rajamma CK (2015) Liver function tests in first and third trimesters of normal pregnancy in a population of North Kerala. J International Medicine Dentistry 2: 215-221.

32. Walker I, Chappell LC, Williamson C (2013) Abnormal liver function tests in pregnancy. BMJ 347: f6055.

33. Miri-Dashe T, Osawe S, Tokdung M, Daniel N, Choji RP, et al. (2014) Comprehensive reference ranges for hematology and clinical chemistry laboratory parameters derived from normal nigerian adults. Plos one 9: e93919.

34. Al-Salahy M, Shnawa B, Abed G, Mandour A, Al-Ezzi A (2016) Parasitaemia and Its Relation to Hematological Parameters and Liver Function among Patients Malaria in Abs, Hajjah, Northwest Yemen. Interdisciplinary Perspectives on Infectious Diseases.

35. Abduljalil K, Furness P, Johnson TN, Rostami-Hodjegan A, Soltani H (2012) Anatomical physiological and metabolic changes with gestational age during normal pregnancy. Clin Pharmacokinet 51: 365-396.

36. Letters (2005) Liver function tests in normal pregnancy: a study from southern India. Indian J Gastroenterol 124: 1-2.

37. Abbassi-Ghanavati M, Greer LG, Cunningham FG (2009) Pregnancy and Laboratory Studies: A reference table for clinicians. Obstetrics Gynecol 114: 1326-1331.

38. Costantine MM (2014) Physiologic and pharmacokinetic changes in pregnancy. Frontiers pharmacol pp: 5-65.

39. Tembe N, Joaquim O, Alfai E, Sitoe N, Viegas E, et al. (2014) Reference values for clinical laboratory parameters in young adults in maputo, mozambique. Plos one 9: e97391.

40. Soma-Pillay P, Nelson-Piercy C, Tolppanen H, Mebazaa A (2016) Physiological changes in pregnancy. Cardiovascular J Africa 27: 89-94. 